\title{
Google Tradutor: Análise de Utilização e Desempenho da Ferramenta
}

\section{Google Translate: Use and Performance Analysis}

\author{
Gislaine Caprioli Costa ${ }^{\mathbf{1}}$ \\ Fátima de Gênova Daniel **
}

Abstract: This qualitative study investigates the use of the Google Translate machine translation tool in a university context, and seeks justification in the scarcity of literature on the subject. The study aims at identifying the profile of users from the courses that use texts in English, and analyzes the translations produced by the tool. Questionnaires were used to identify the users' profiles, and the performance analysis focused on lexical, morphosyntactic and socio-cultural deviations as criteria. The participants mostly presented proficiency level between basic and intermediate, and $93 \%$ claimed to be users of the tool, declaring a high degree of confidence in its effectiveness and a belief that it partially meets their expectations. Regarding the performance of the tool the main problems were in terms of morphosyntax, and deviations involving lack of cultural adequacy.

Keywords: Translation; human translator; machine translation; Google Translate; technology.

\footnotetext{
${ }^{1}$ Formada em Letras - Tradutor pela Universidade Sagrado Coração (USC) em Bauru-SP. Email: gih.caprioli@gmail.com.

** Profa. Dra. Fátima de Gênova Daniel, dos cursos de Graduação e Pós-Graduação da USC, Bauru-SP. Email: fatimagedaniel@gmail.com
} 
Resumo: Este estudo qualitativo investiga o uso da ferramenta de tradução automática Google Tradutor em contexto universitário e busca justificativa na escassez de literatura sobre o tema. Os objetivos principais são identificar o perfil de usuários nos cursos que utilizam textos em língua inglesa e discutir o desempenho da ferramenta em suas traduções. Questionários foram utilizados para identificar o perfil dos usuários, e a discussão do desempenho focou nos critérios de desvios lexicais, morfossintáticos e socioculturais. Os participantes apresentaram nível de proficiência entre básico e intermediário e 93\% deles afirmaram ser usuários da ferramenta com alto grau de confiabilidade em sua eficácia e que ela atende parcialmente suas expectativas. Quanto ao desempenho, os problemas principais foram de ordem morfossintática e desvios envolvendo questões de adequação cultural.

Palavras-chave: Tradução; tradutor humano; tradução Automática; Google Tradutor; tecnologia.

\section{Introdução}

A crescente necessidade do intercâmbio de informações entre as culturas faz com que a comunicação entre elas tenha que ser imediata e 0 mais precisa possível. A tecnologia tenta meios de auxiliar nesta interação entre culturas e as ferramentas de Tradução Automática (TA) são indicativas disso.

Um diferencial muito procurado no mercado de trabalho é 0 conhecimento e a proficiência de outros idiomas. Infelizmente, o aprendizado de línguas estrangeiras não tem sido de muita eficácia em nosso país, principalmente em se tratando de alunos da rede pública de ensino, deixando essa tarefa para os institutos especializados, que podem ser dispendiosos, dificultando para a grande população conhecer outros idiomas.

Com a internet em seu ápice, houve uma intensificação em transmissões de informação e se multiplicou a presença de diferentes línguas em nossa aldeia global (Alfaro 1998). Os desenvolvedores do tradutor 
COSTA, G. C.; DANIEL, F. de G. - Google Tradutor: Análise de Utilização e Desempenho da Ferramenta

automático criam ferramentas para suprir a necessidade de facilitar o contato entre falantes de idiomas diferentes.

No contexto universitário, as ferramentas de TA são muito utilizadas por alunos que necessitam realizar leituras de textos acadêmico-científicos em outras línguas, em especial a língua inglesa. Apesar de alguns a terem estudado em institutos de idiomas, não possuem o nível de fluência ou segurança necessário para traduzir sem o uso de ferramentas de auxílio. Há algumas instituições que descrevem as habilidades dos falantes de inglês como língua estrangeira. Nesta pesquisa, os cinco níveis de proficiência de acordo com a ACTF (American Council On The Teaching Of Foreign Languages) foram considerados apenas como guia para o entendimento dos dados pelos leitores finais. Os cinco níveis de proficiência utilizados pela ACTF são: Distinguished, Superior, Advanced, Intermediate e Novice. Desses níveis, os mais comuns são Advanced (Avançado), Intermediate (Intermediário) e Novice (Básico). 0 estudo define os níveis de acordo com as quatro macro-habilidades ${ }^{1}$.

$\mathrm{Na}$ fala, as pessoas de nível avançado conseguem se comunicar sobre diversos assuntos e improvisar por possuírem um léxico abundante. Na escrita, estão aptos a escrever discursos formais e informais, com parágrafos longos, conectados e bem estruturados. Na compreensão auditiva, são capazes de entender a ideia principal do que é falado e a maioria dos detalhes em discursos conectados sobre uma variedade de tópicos de interesse geral. Na leitura, podem entender a ideia principal e detalhes de textos narrativos e descritivos. São capazes de ler a respeito de temas novos, mas precisam que 0 texto utilize estruturas claras e mais previsíveis.

As pessoas de nível intermediário conseguem criar o discurso no momento da fala se for a respeito de um tema conhecido ou recombinar algo já aprendido para expressar o que precisa falar no momento, criando perguntas simples para serem usadas em situações de emergência. Na escrita, fazem ou respondem questões mais simples. Na compreensão auditiva,

\footnotetext{
${ }^{1}$ Dados obtidos no relatório ACTFL Proficiency Guidelines 2012, disponível em: বttp:// www. actfl.org/ files/ public/ ACTFLProficiencyGuidelines2012_FINAL. pdf>. (25/08/2012).
} 
conseguem apreender informações passadas de maneira simples e tópicos familiares ou mensagens que não precisam de contexto. Dependem da redundância, repetição e paráfrase para auxiliar na compreensão. A informação, quando transmitida de maneira simples, previsível e com pouca conexão, pode ser compreendida completamente.

As pessoas de nível básico conseguem falar frases curtas, geralmente relacionadas ao seu dia a dia. Não produzem, apenas reutilizam frases e palavras conhecidas. Sua escrita é basicamente composta de palavras ou frases simples, não conseguindo conectar o bastante para criar parágrafos. São capazes de preencher informações em formulários e documentos mais simples. Na compreensão auditiva, entendem palavras-chave e expressões clichês que possuem estruturas mais simples. Entendem a leitura realizada se o tema ou contexto já for familiar ou os textos possuírem apoios extralinguísticos (imagens, por exemplo). São mais capazes de compreender um texto quando é possível antecipar as informações que vão lendo.

As quatro macro-habilidades em compreensão e produção em línguas são: speaking (fala), writing (escrita), listening (compreensão auditiva) e reading (leitura). Leitura e escrita fazem parte da compreensão e produção escrita, enquanto a compreensão auditiva e fala fazem parte da compreensão e produção oral. Para J ANULEVIČIENĖ E KAVALIAUSKIENÉ (2002), há ainda a quinta habilidade, a da tradução. Ela é compreendida como a habilidade de fazer uma troca rápida de códigos em duas línguas e de forma alternada, sem preparação ou tempo para pensar.

Este trabalho investigativo surgiu de dois questionamentos: o primeiro com relação ao usuário de ferramenta de TA em contexto universitário, seu perfil e suas expectativas quanto à eficácia da ferramenta e o segundo sobre o próprio desempenho da ferramenta em traduções para a língua portuguesa.

O objeto de estudo é o Google Tradutor (GT) e o objetivo geral, portanto, é investigá-lo por ser de uso corrente para traduções. Como objetivos específicos, este estudo pretende delinear o perfil dos usuários universitários nos cursos que utilizam textos em língua inglesa apresentados em sala de aula e também discutir a eficácia da ferramenta na tradução de 
COSTA, G. C.; DANIEL, F. de G. - Google Tradutor: Análise de Utilização e Desempenho da Ferramenta

textos relacionados às áreas dos cursos escolhidos, com posterior análise dos desvios mais significativos para a compreensão do usuário.

Este estudo busca justificativa no fato de delinear o perfil do usuário da ferramenta em contexto de uma universidade privada, detectar se há preconceito quanto ao seu uso e se ela atende às necessidades mínimas de compreensão dos textos traduzidos.

A discussão dos desvios encontrados nas traduções servirá como material de análise para os alunos e professores dos cursos de Letras e Tradutor, já que, apesar da constante evolução da TA, seus resultados precisam ser aprimorados ainda mais (RINO; SPECIA 2002). Devido à falta de informações sobre 0 assunto, a pesquisa também se justifica por contribuir com material para reflexão dos tradutores em formação e poderá também ser ponto de partida para que ações sejam implementadas no contexto investigado no sentido de oferta de encontros e oficinas para que 0 instrumento de tradução possa ser utilizado em seu potencial máximo pelos docentes e discentes.

\section{Discussão Teórica}

\subsection{GLOBALIZAÇÃO, TECNOLOGIA E TRADUÇÃO}

A tecnologia pode ser uma aliada do conhecimento de novas culturas. Ela está presente também no trabalho diário, porque muitas ferramentas são criadas para aprimorar e auxiliar as pessoas.

Franz J osef Och entrou na empresa Google em 2004 para liderar uma equipe voltada para a criação do Google Tradutor $^{2}$. Entre 2006 e 2008, a ferramenta suportava apenas os idiomas inglês, espanhol, francês e alemão.

\footnotetext{
2 Informações retiradas do perfil de Franz J osef Och em Research at Google, disponível em: বhttp:// research.googl e.com/ pubs/ och. html>. (27/ 05/ 2012).
} 
Em fevereiro de 2009, já cobria $98 \%$ dos idiomas lidos na internet, totalizando

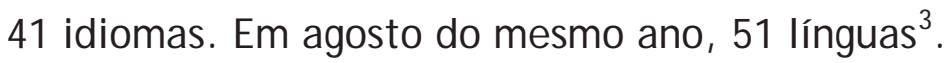

É visível que o crescimento no número de idiomas suportados e atualizações com novos recursos tentam levar o Google Tradutor para mais perto do usuário.

Hoje, conta com 71 idiomas, incluindo os chamados "idiomas alfa", que podem ter uma qualidade de tradução menos confiável enquanto ainda são trabalhados ${ }^{4}$. A denominação alfa é própria do site Inside Google Translate e, possivelmente, trata dos idiomas ainda em fase de experimento na ferramenta. Também houve a criação e o desenvolvimento de mais serviços acoplados.

De acordo com SMAAL (2010), a intenção das empresas que desenvolvem ferramentas de tradução automática é diminuir a distância entre as línguas. Só o fato de o Google Tradutor ser disponibilizado gratuitamente e online facilita para que qualquer pessoa com acesso à internet tenha contato com ele, aumentando sua popularidade.

Desde sua criação, o GT permite contribuições de internautas que podem sugerir uma tradução melhor, editando a que foi inicialmente apresentada pela ferramenta. LeAL (2009) indica em seus estudos que tais contribuições ajudam no aperfeiçoamento da ferramenta, mantendo a continuidade da evolução.

De acordo com Murano (2010), a principal fonte de documentos traduzidos pelo Google Tradutor é a internet. A ferramenta trabalha com base na tradução automática por análise estatística, que detecta padrões em textos bilíngues criados por tradutores humanos e determina qual a tradução considerada mais adequada para o texto que the é apresentado.

Muitas das traduções que foram implementadas no banco de dados da ferramenta são de vários documentos bilíngues oficiais, inclusive das Nações Unidas (GOMEs 2010).

\footnotetext{
3 Informações retiradas do Google History, disponível em: «ttp:// www. google. com/about/ company/ history/ $>$. (27/05/2012).
4 Informações retiradas do site Inside Google Translate, disponível em: <http:// translate. google.com/ about/ >. (19/ 10/2013).
} 
COSTA, G. C.; DANIEL, F. de G. - Google Tradutor: Análise de Utilização e Desempenho da Ferramenta

A equipe de Franz Josef Och informou que há muitas maneiras de aumentar a qualidade da ferramenta. As sugestões dos usuários também alimentam o banco de dados. Um dos recursos mais importantes desse tradutor é a capacidade de encontrar documentos traduzidos na internet e incorporar ao seu banco de dados, tendo em vista a correlação direta entre a quantidade de dados e o resultado final da tradução (Murano 2010).

A ferramenta não é perfeita e autores como GOMEs (2010) afirmam que, ao se dedicar mais tempo em sua utilização, é possível notar que a tradução é precisa em alguns pontos, entretanto, pode produzir sentenças confusas e mal feitas em alguns casos. Por desconhecerem esse fato, os usuários leigos se decepcionam ao verificarem que a ferramenta não é tão perfeita quanto os desenvolvedores afirmam, os quais criam grande expectativa diante do texto traduzido, sendo que muitos não enfatizam a importância do aperfeiçoamento do trabalho humano de traduzir (ALFARO; Dias 1998).

Para eliminar essa decepção é necessário enxergar a ferramenta como um auxílio ao trabalho do tradutor humano e não como uma ferramenta tradutora completa.

Há limitação nas ferramentas de TA, uma vez que elas não levam em consideração características históricas, sociais e polissêmicas dos textos apresentados, as quais não podem ser implantadas no banco de dados devido a sua complexidade. Portanto, ainda que haja constante evolução, essa é uma barreira intransponível.

\subsection{PERSPECTIVAS PARA O FUTURO DA TRADUÇÃO}

Para alcançar uma posição firme e sólida no mercado de trabalho, profissionais de diversas áreas devem saber utilizar bem as ferramentas que estão disponíveis.

Em específico, para um tradutor aprendiz e até mesmo para um profissional, o conhecimento do potencial das ferramentas de TA é tão importante quanto o de outras ferramentas de auxílio, como dicionários 
eletrônicos, softwares de edição de texto e memórias de tradução (ARAÚjo 2010).

Com base na teoria de aproveitamento, RESENDE e SouZA (2011) afirmam que a globalização implica na necessidade de comunicação entre povos de diferentes culturas e línguas, que ocorre em meio à tradução. A globalização implica em desenvolvimento também na tecnologia.

É pretensioso exigir que a tradução automática seja totalmente autônoma e de grande qualidade, já que até mesmo a tradução humana passa por revisão para garantir confiabilidade ao trabalho (SLOCUM 1975 apud ALFARO 1998). Há tradutores que acreditam no uso consciente da ferramenta e assumem a evolução da tecnologia como forma de auxílio.

Conforme a disponibilidade de ferramentas que afirmam ser de tradução automática aumenta, surgem muitas críticas de usuários e profissionais ao uso delas. A respeito das críticas, Bernabio (2010) afirma que, muitas vezes, as opiniões contrárias podem ser classificadas como equivocadas, porque muitos profissionais acreditam que o desenvolvimento da tradução automática pode ameaçar seus empregos, já que há usuários afirmando que a TA pode substituir o trabalho do tradutor humano. Para LIMA (2011), as críticas ao uso são válidas, mas nem sempre justas. 0 que ele discute em seu estudo e o que se pretende reforçar é que há imensas possibilidades de utilização das ferramentas que o autor classifica como sendo de tradução eletrônica, e é mais conhecida como tradução automática.

SANTOS (2006) elucida esse conceito de auxílio quando reforça que 0 objetivo das ferramentas de TA é facilitar o trabalho intelectual dos seres humanos e não substituí-lo. Dessa maneira, o tradutor está livre das tarefas repetitivas e aproveita o que já foi feito pela ferramenta.

Outros tradutores, como J oÃo AzenHA J ÚNIOR (apud Benedetti; Sobral 2003), afirmam que os programas de tradução ajudam na versão bruta do trabalho, mas que é responsabilidade do tradutor alterar o que ele acredita que deve ser feito. Assim, ele se torna um tradutor crítico e o texto não sairá com a marca de um programa e sim com sua assinatura, com as escolhas feitas por ele. 
COSTA, G. C.; DANIEL, F. de G. - Google Tradutor: Análise de Utilização e Desempenho da Ferramenta

Para ARAújo (2002), as traduções obtidas por ferramentas são indicativas e precisam apenas criar compreensibilidade para que o usuário possa entender no geral o texto que é apresentado. Ainda assim, é preciso que um usuário fluente nas línguas de partida e chegada identifique 0 conteúdo completo do texto, servindo o tradutor automático como um auxiliador. BRum (2008) destaca que, se a qualidade do texto não for um fator importante para o entendimento geral do conteúdo, a tradução automática servirá de apoio ao trabalho do tradutor humano, já que ele está preparado para condições de complexidade e má qualidade no texto original.

Dessa forma, como há autores que aceitam o auxílio do Google Tradutor e outros que recusam terminantemente, há aqueles que são extremamente favoráveis ao uso de TA e sugerem que haverá mudanças drásticas em um tempo futuro. Em uma reportagem para a revista Veja, que foi muito comentada por vários profissionais da área, PAVÃO J ÚNIOR (2010) afirma que, com o avanço das ferramentas de TA, a exigência de aprender um idioma estrangeiro poderá ser abalada. Nesse caso, ele ignora por completo 0 enriquecimento vocabular, histórico e cultural que uma experiência dessas traz para $o$ aluno.

O número de recursos cresce, dando mais agilidade ao Google Tradutor, o que pode culminar em pensamentos errôneos de que ele está acabado e pronto para substituir um tradutor humano.

RINO E SPECIA (2002) trazem um questionamento ainda atual: as maiores restrições aos sistemas de TA são impostas pela falta de soluções computacionais para os problemas linguísticos. Ainda que haja evolução nas ferramentas, elas sempre esbarram nessa dificuldade. Somente um tradutor humano pode supri-las.

É possível verificar que há dois aspectos relevantes sobre a TA: o proveito que a tecnologia pode trazer ao profissional, apesar das limitações existentes, e a contribuição que o profissional pode dar à ferramenta, se desejar, para que o desenvolvimento da tecnologia continue (ARAújo 2010). 


\section{Metodologia de Pesquisa}

Para investigar a percepção dos alunos a respeito da ferramenta, optou-se pela realização de uma pesquisa qualitativa, e os dados foram obtidos por meio de um questionário que apresentou duas partes: dados pessoais do usuário e percepções do usuário quanto ao uso da ferramenta.

Os participantes foram 68 alunos dos cursos de Arquitetura e Urbanismo, Ciências da Computação e Engenharia Química em contexto privado de ensino superior; eles foram selecionados por terem aulas em laboratório de informática e pelo fato de seus professores utilizarem bibliografia em outros idiomas, com mais frequência na língua inglesa, o que pode levá-los ao uso do Google Tradutor e a terem uma opinião formada a respeito de sua utilidade. A pesquisa foi norteada pelos seguintes questionamentos:

- Perfil do usuário:

1) Qual o perfil do usuário no contexto investigado quanto à idade e experiência anterior de aprendizagem com a língua?

2) Qual o nível de proficiência linguística?

3) Quais as línguas mais traduzidas?

4) Há algum preconceito quanto ao seu uso?

- A eficácia da ferramenta:

1) Quais os desvios mais significativos para a compreensão do usuário percebidos nas traduções?

2) Em que medida a ferramenta pode auxiliar os usuários em suas tarefas de leitura de textos traduzidos por ela? 
COSTA, G. C.; DANIEL, F. de G. - Google Tradutor: Análise de Utilização e Desempenho da Ferramenta

Com o questionário analisado, foi possível responder as perguntas relativas ao perfil dos usuários participantes. Em seguida, foi feita a análise de fragmentos dos textos indicados pelos professores de cada curso em questão, com a finalidade de investigar em qual medida a ferramenta pode ser de auxílio aos universitários. A discussão dos resultados focou nos desvios lexicais, morfossintáticos e socioculturais presentes nos fragmentos dos textos que foram escolhidos aleatoriamente para não interferir na análise final, evitando suavizar ou exacerbar os desvios cometidos pela ferramenta. Os textos indicados pelos professores eram em língua inglesa por serem mais recorrentes na bibliografia do curso, e foi optado discutir a tradução para a língua portuguesa por ser a língua materna dos universitários participantes desta pesquisa. 0 estudo encontra validade contextual local, sem aspirar a generalizações.

\section{Análise e Discussão dos Dados}

Neste item, será apresentada a análise e interpretação dos dados obtidos com a aplicação do questionário com os alunos e os resultados das traduções feitas pelo Google Tradutor.

As turmas que participaram do estudo foram:

a) Arquitetura e Urbanismo, $2^{\circ}$ ano, com 22 alunos;

b) Ciência da Computação, 40 ano, com 24 alunos;

c) Engenharia Química, 5o ano, com 22 alunos.

Os professores participaram indicando os autores que já trabalharam em sala de aula. 


\subsection{DELINEANDO O PERFIL DOS USUÁRIOS}

Este estudo envolveu 68 alunos, com predominância de participantes do sexo masculino, 48 homens e 20 mulheres. Os dados são justificados pela predominância masculina nos cursos investigados.

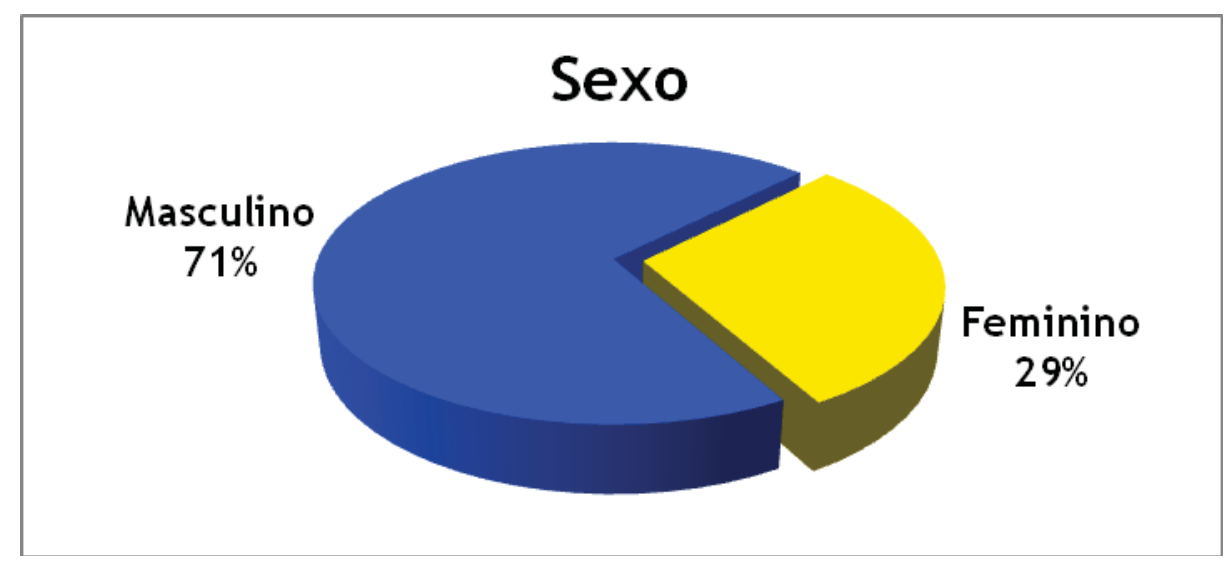

Gráfico 1 - Sexo dos participantes

A idade predominante dos participantes varia entre 18 e 26 anos (72\%), o que nos remete a um público bastante jovem. Acima de 30 anos são 15\% dos sujeitos, o que tornou o grupo heterogêneo no aspecto idade, conforme gráfico a seguir: 
COSTA, G. C.; DANIEL, F. de G. - Google Tradutor: Análise de Utilização e Desempenho da Ferramenta

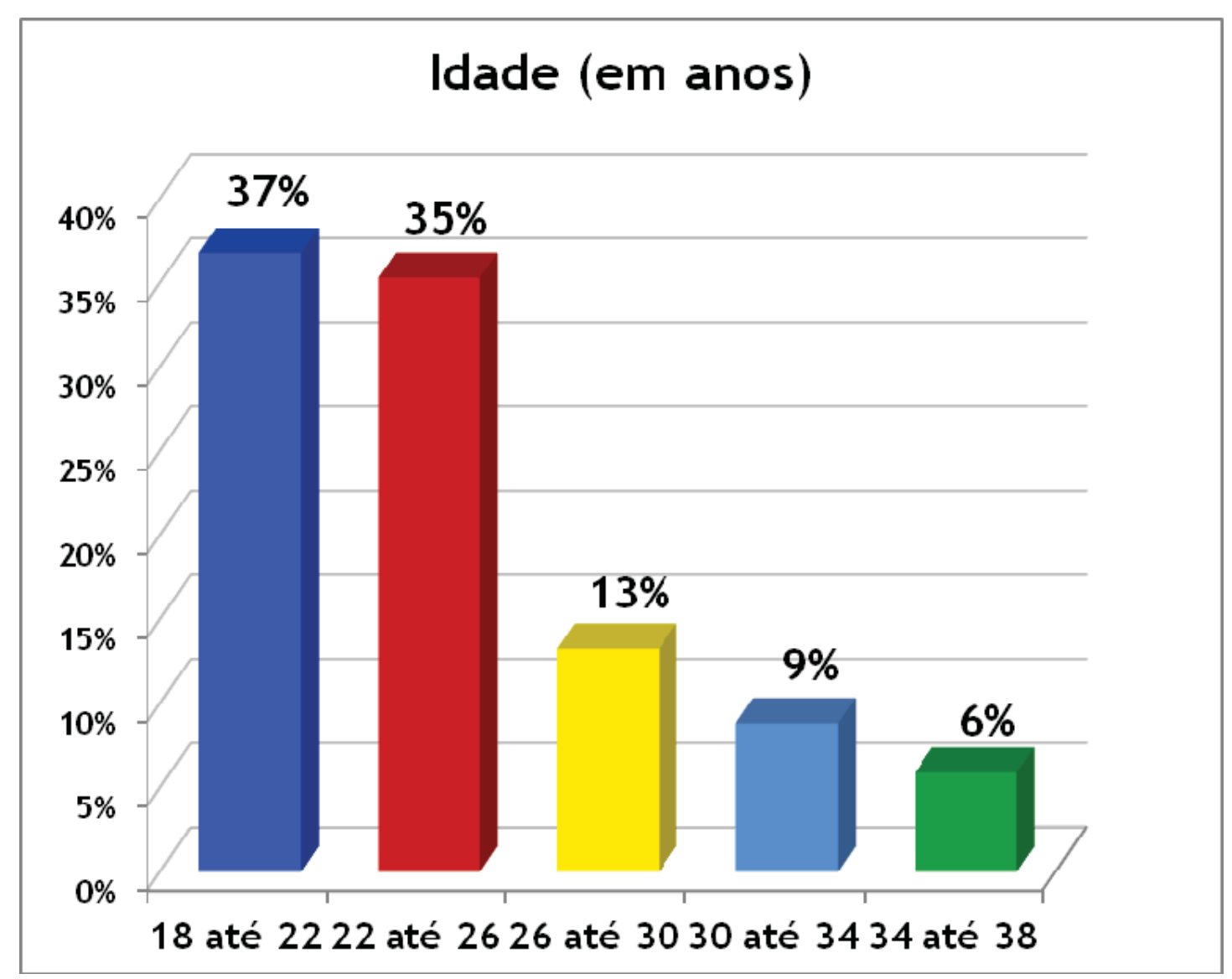

Gráfico 2 - Idade dos participantes

Quanto ao contato prévio com a língua inglesa em contexto de instituto de idiomas, 72\% dos entrevistados afirmam ter tido, ainda que breve. Este é um quadro comum em nosso país, considerando os resultados insatisfatórios quanto ao aprendizado de idiomas em escolas regulares.

Outra indagação importante para o estudo foi quanto ao nível de proficiência alegado pelos participantes. Eles definiram o nível de proficiência de acordo com a própria perspectiva, não foi oferecida uma descrição de níveis para se basearem. A descrição indicada na Introdução foi usada apenas como base para o entendimento do leitor da pesquisa.

O questionário identificou uma maioria em dois níveis especificamente: básico/ iniciante (37\%) e intermediário (39\%). 


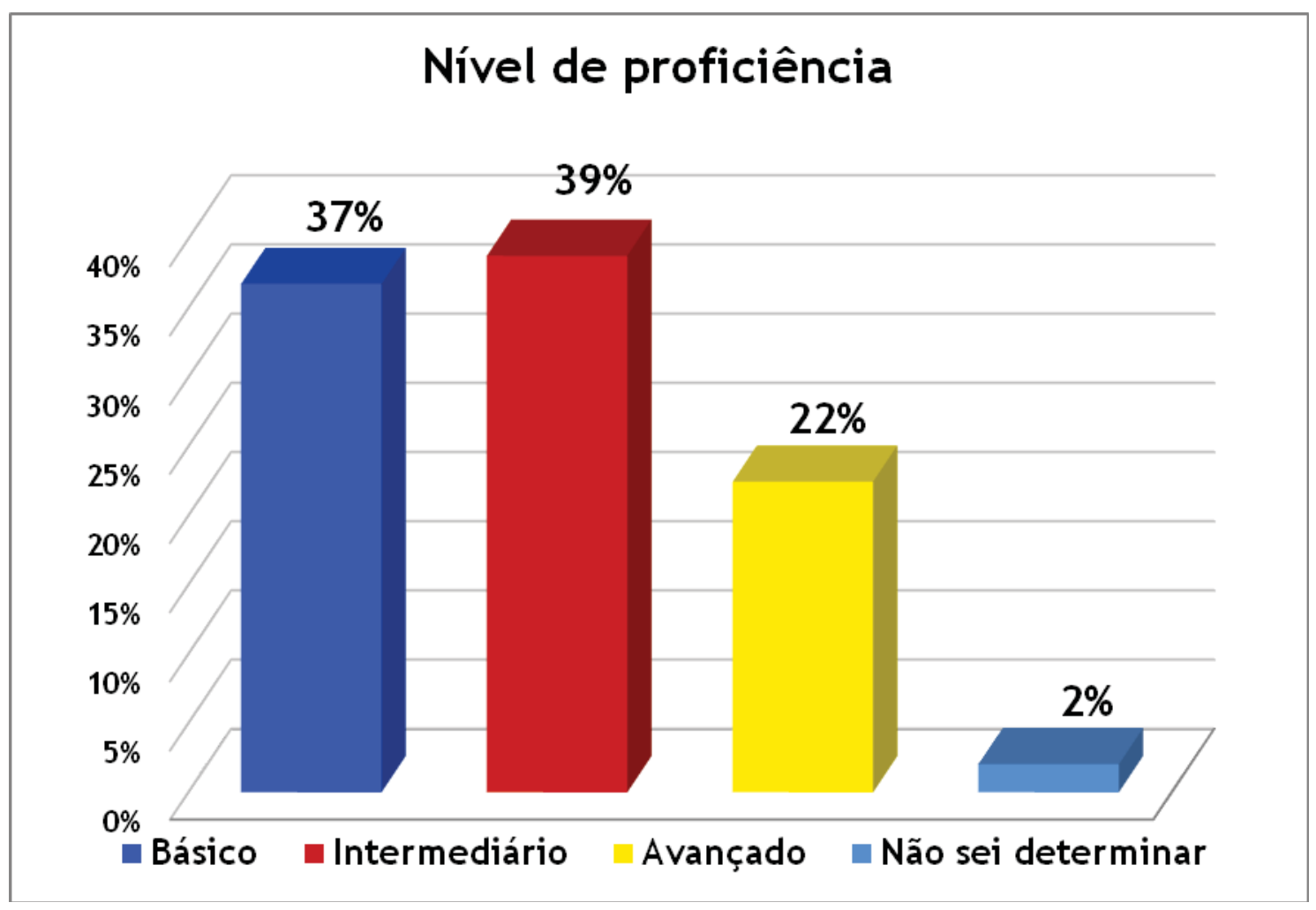

Gráfico 3 - Nível de proficiência

A intenção da análise era triangular os dados obtidos no item "Nível de proficiência" e, de certa forma, detectar quais habilidades são mais requisitadas e desenvolvidas. Os entrevistados puderam escolher mais de uma resposta, informando ter várias habilidades.

As habilidades de compreensão e produção escrita foram as mais mencionadas pelos participantes (conforme gráfico abaixo), as habilidades de compreensão e produção oral ficaram em número inferior, com alguns deles afirmando não ter habilidade alguma. 
COSTA, G. C.; DANIEL, F. de G. - Google Tradutor: Análise de Utilização e Desempenho da Ferramenta

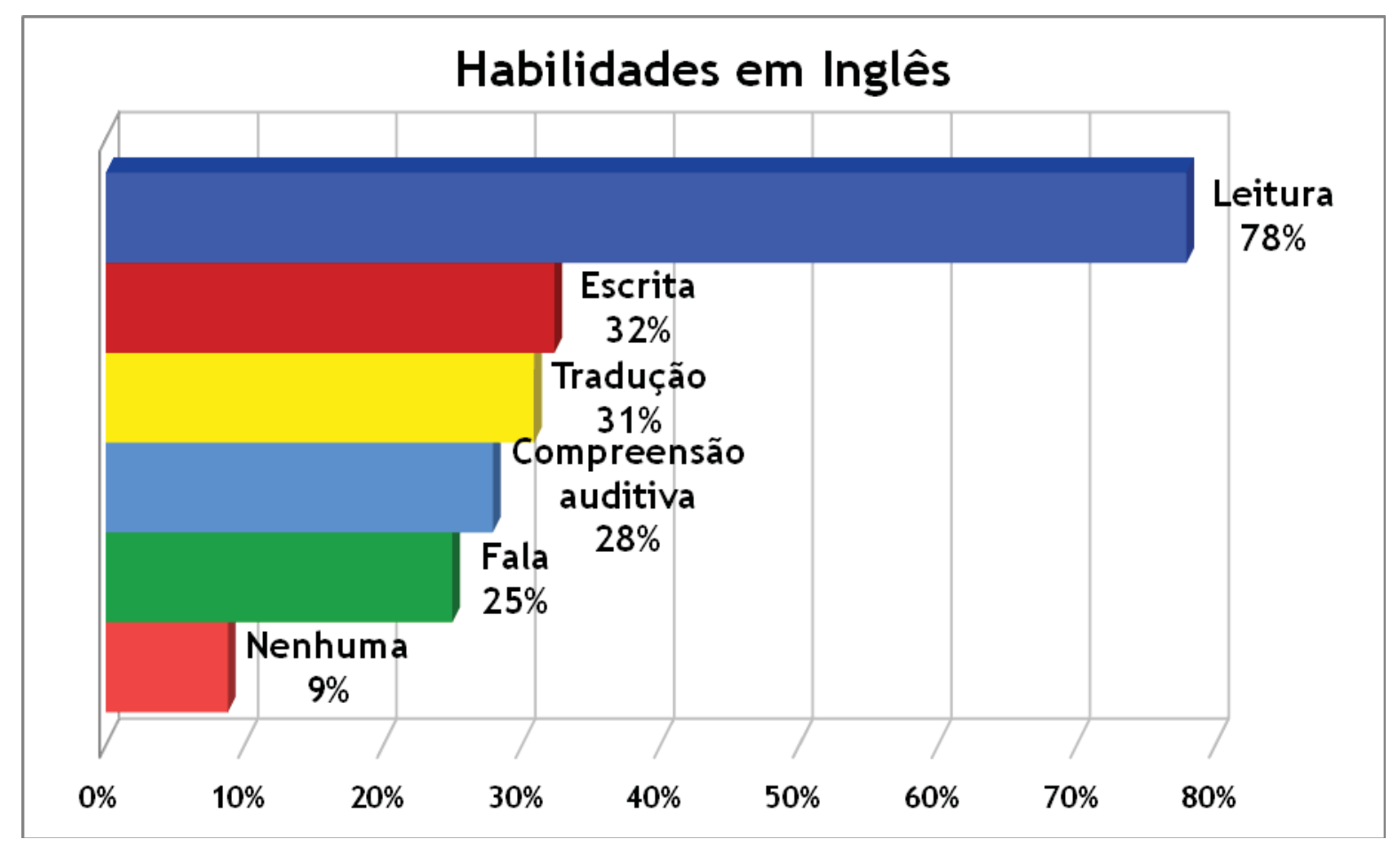

Gráfico 4 - Habilidades em inglês

A habilidade em tradução, representada em $31 \%$ das respostas ( 21 pessoas), foi uma surpresa. Independentemente do nível de proficiência declarado, o aluno se diz capaz de realizar traduções. Fica o questionamento se 0 aluno tem consciência do que seria tal habilidade e, caso soubesse, se ainda se declararia habilitado para tal.

Cruzando os dados desta habilidade e o nível de proficiência declarado, o estudo revelou que os alunos em nível intermediário se julgam mais habilidosos para realizar traduções (33\%). Outro dado importante foi o grupo de nível indefinido ou nenhum, mas que traduz textos (24\%), e aqueles de nível avançado que, teoricamente, seriam mais bem preparados linguisticamente para realizar traduções, apenas $29 \%$ deles alegam ter tal habilidade. 


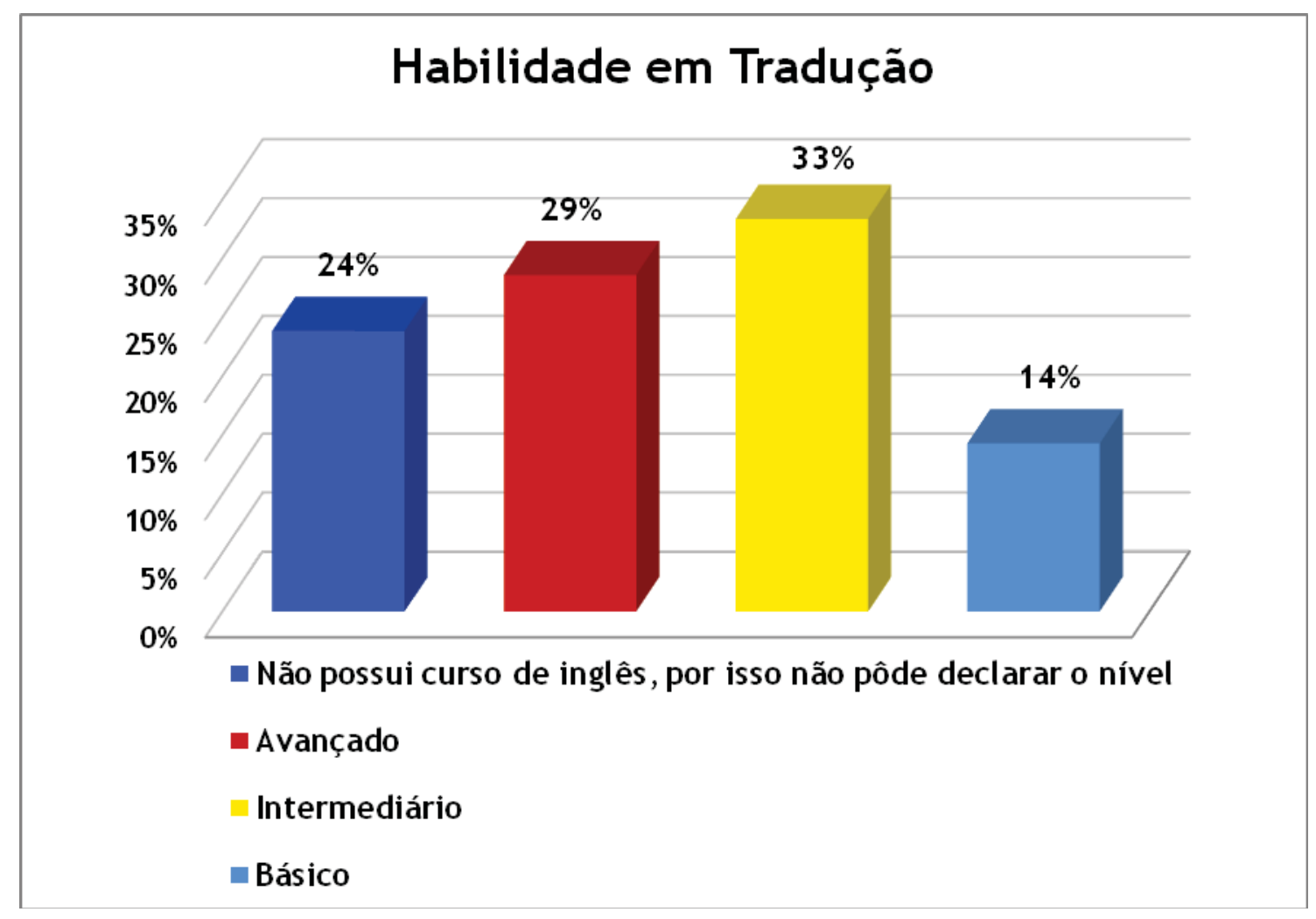

Gráfico 5 - Habilidade em tradução

A habilidade leitora foi verificada como sendo a mais desenvolvida (presente em 78\% das respostas) entre os investigados. 0 que pode ser historicamente justificado uma vez que esta é uma habilidade focada, de maneira geral, nos cursos regulares de língua inglesa, principalmente pela não utilização da língua-alvo em sala de aula. O trabalho com textos é uma prática comum em salas de aula e, por consequência, há a percepção que desenvolvemos esta habilidade mais do que as demais. 
COSTA, G. C.; DANIEL, F. de G. - Google Tradutor: Análise de Utilização e Desempenho da Ferramenta

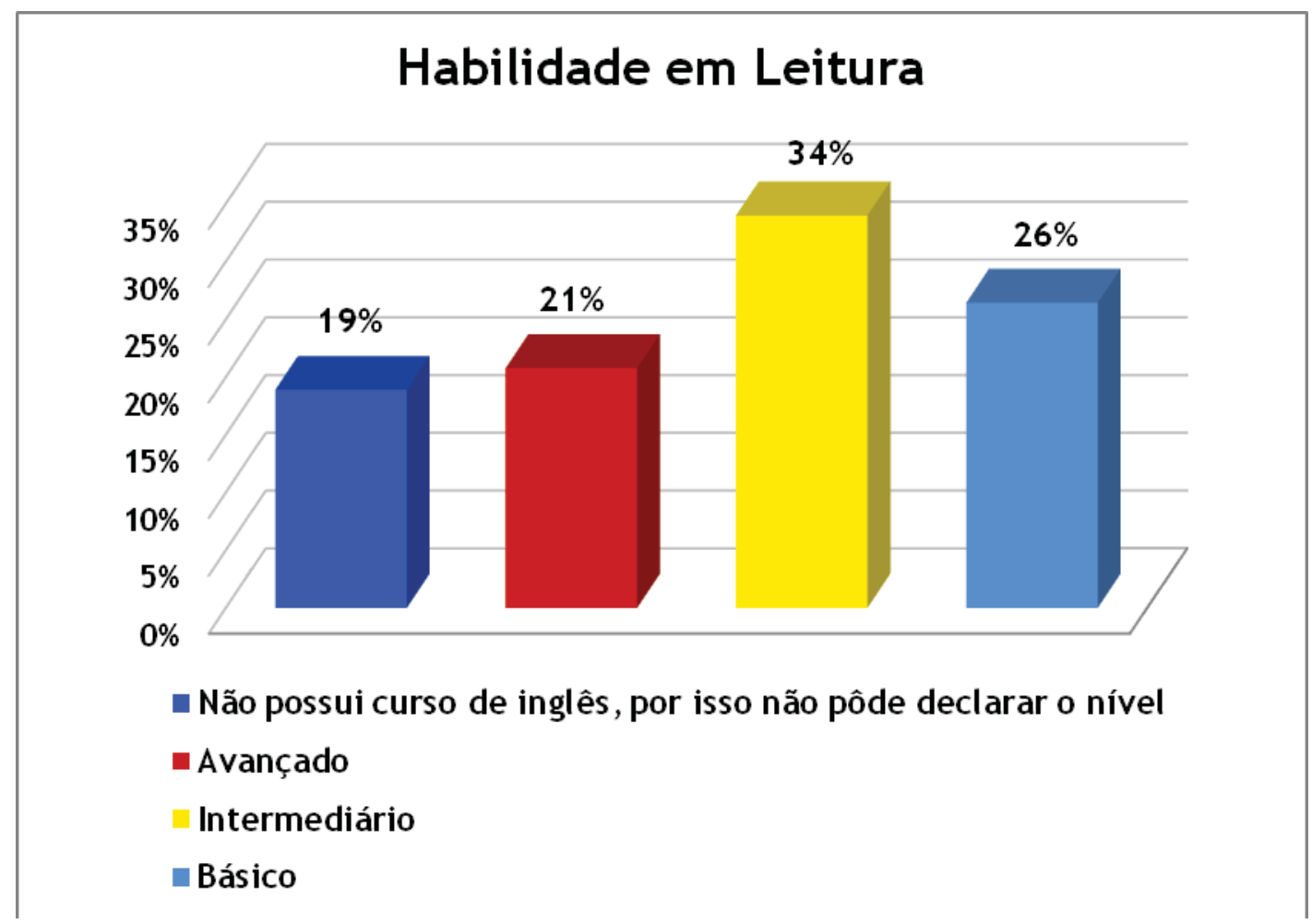

Gráfico 6 - Habilidade em leitura

De acordo com Coelho (2005), há uma crença entre os professores e a direção das escolas brasileiras de que os alunos veem a disciplina Língua Inglesa como inferior e que só é necessária para o vestibular, focando apenas na leitura. MARTINS (2007) reforça essa ideia a respeito do contexto escolar brasileiro afirmando que o professor está utilizando a língua-alvo na sua forma oral cada vez menos, portanto, também diminui a exposição do aluno a essa habilidade. 0 aspecto do currículo que tem sido mais favorecido é o ensino de língua estrangeira voltado para a leitura. A conclusão que Coelho (2005) chega a respeito do assunto é a necessidade de uma reconfiguração nas propostas curriculares para que o ensino de um idioma seja trabalhado em sua totalidade (escrita, leitura, fala e compreensão auditiva).

A utilização de fontes em língua inglesa é uma prática constante no contexto investigado, pois títulos internacionais são usados na bibliografia do plano de ensino da disciplina. Apenas $10 \%$ dos envolvidos afirmam sempre 
utilizar textos em outros idiomas em seus estudos pessoais, e o idioma mais citado foi o inglês (81\%), seguido do alemão (18\%) e espanhol (1\%).

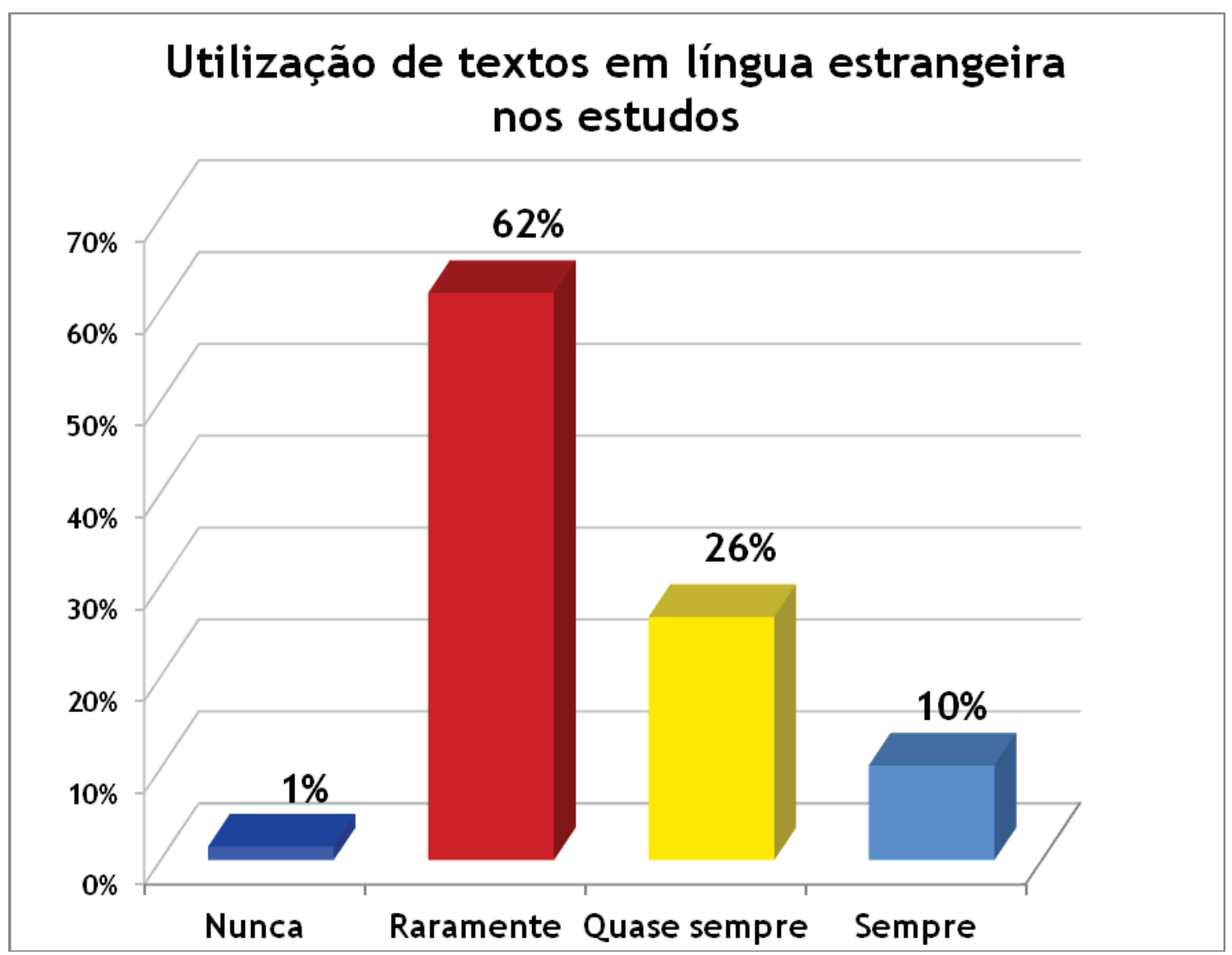

Gráfico 7 - Textos em língua estrangeira

\subsection{A FERRAMENTA GOOGLE TRADUTOR}

A maioria dos entrevistados conhece o Google Tradutor. O resultado apontou $97 \%$ do total afirmando conhecer a ferramenta, o que pode ser justificado por sua popularidade. Em uma matéria de 2012, MURPHY afirma que - Google Tradutor conta com 200 milhões de usuários mensais. A soma desses usuários provém apenas dos dados de acesso da página da ferramenta, mas há usuários que utilizam via navegador Google Chrome, celulares e pelo site 
COSTA, G. C.; DANIEL, F. de G. - Google Tradutor: Análise de Utilização e Desempenho da Ferramenta

YouTube. A divulgação demonstra o alcance global que a ferramenta está tendo desde sua criação.

\begin{tabular}{|c|c|c|}
\hline Idade & Sim & Não \\
\hline 18 até 22 & 25 & 0 \\
\hline 22 até 26 & 24 & 0 \\
\hline 26 até 30 & 9 & 0 \\
\hline 30 até 34 & 5 & 1 \\
\hline 34 até 38 & 3 & 1 \\
\hline Total: & 66 & 2 \\
\hline
\end{tabular}

Tabela 1 - Idade x conhecimento do GT

Das 66 pessoas que afirmaram conhecer o Google Tradutor, 63 delas $(93 \%)$ indicam utilizá-la. Nota-se que a grande maioria das pessoas que conhece a ferramenta confia nela o bastante para usá-la.

Um dado relevante é que, apesar de $76 \%$ dos usuários que utilizam a ferramenta alegarem confiar nela, os mesmos afirmam haver a necessidade de checar os dados em outras fontes.

\begin{tabular}{l|c|c|}
\hline $\begin{array}{l}\text { As traduções sugeridas pela ferramenta geram } \\
\text { confiabilidade? }\end{array}$ & Quantidade & Porcentagem \\
\hline Sim, mas necessitam de confirmação em outras fontes & 50 & $76 \%$ \\
\hline Não, pois apresentam muitos erros & 11 & $17 \%$ \\
\hline Sim, são perfeitas & 3 & $5 \%$ \\
\hline Não soube informar & 2 & $3 \%$ \\
\hline Total: & 66 & $100 \%$ \\
\hline
\end{tabular}

Tabela 2 - Confiabilidade nas traduções

Ao analisar o gráfico a seguir, é perceptível que a utilização é mais constante para os usuários com faixa etária entre 18 a 30 anos e com menor frequência para aqueles com 30 ou mais. 


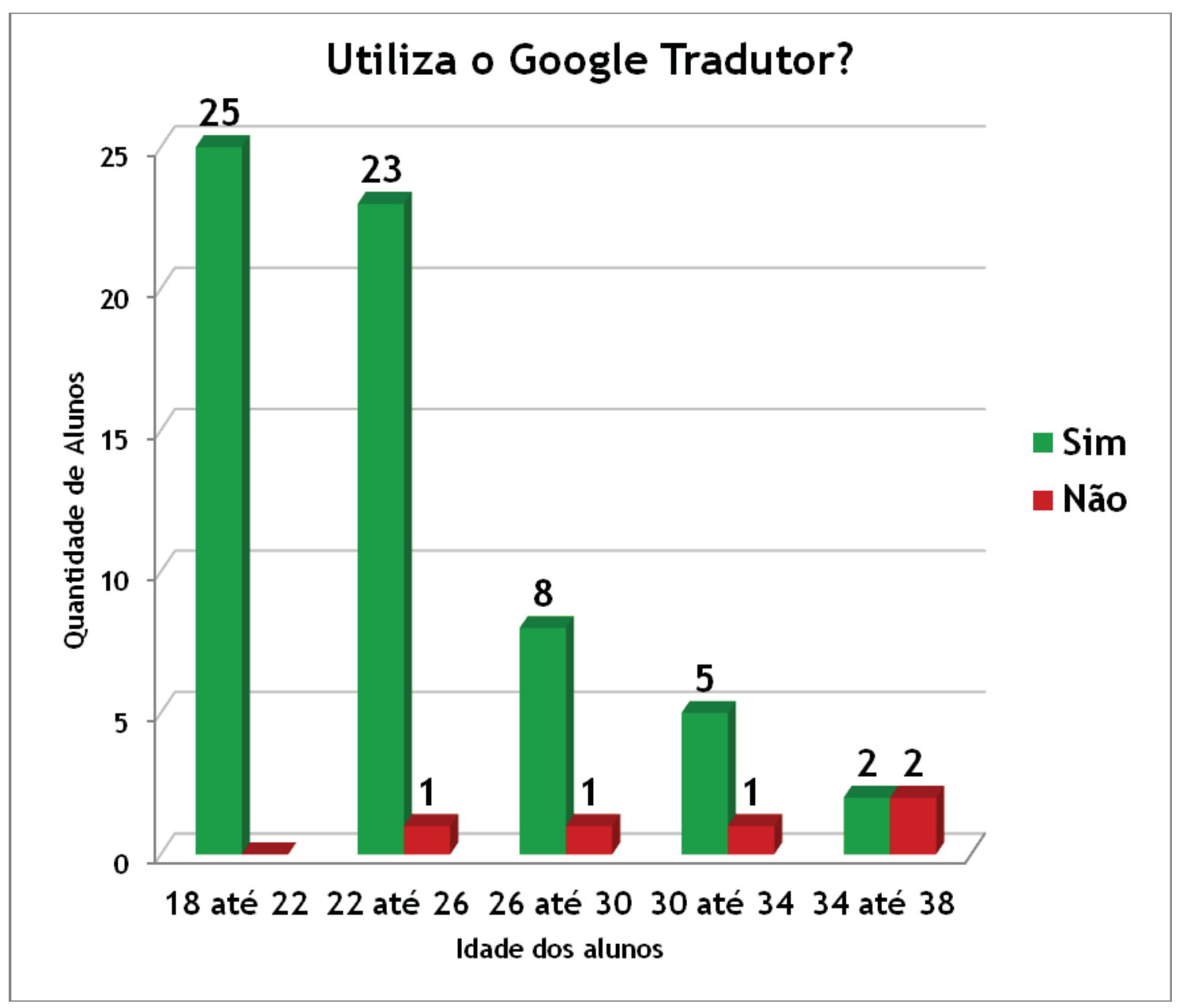

\section{Gráfico 8 - Utilização GT x Idade}

Os alunos, de acordo com sua faixa etária, podem ser divididos entre: a) Geração X: entre 32 e 51 anos; b) Geração Y: entre 20 e 31 anos; c) Geração Z: entre 14 e 19 anos $^{5}$.

As pessoas da Geração X cresceram na época da ditadura militar, sob a vigência da censura, onde eram pouco acostumados a expor suas opiniões. As da Geração Y conheceram a redemocratização e participaram do início da internet, com a qual cresceram. A Geração Z conviveu desde o início com a internet, o celular, as redes sociais e os blogs. Para ela, o mundo é conectado

\footnotetext{
${ }^{5}$ Informações encontradas na pesquisa São Paulo em Foco - Gerações $X, Y$ e Z, disponível em: বhttp:/ / www. questmkt. com. br/ questblog/ ?p=172>. (20/08/ 2012).
} 
COSTA, G. C.; DANIEL, F. de G. - Google Tradutor: Análise de Utilização e Desempenho da Ferramenta

e elas são as pessoas sem barreiras geográficas. Na presente pesquisa, a relação de idade versus o conhecimento e utilização do Google Tradutor está interligada, e a maioria dos entrevistados que usam a ferramenta é da geração $Y$.

Quanto aos objetivos tradutórios ao utilizar o Google Tradutor, os dados apontam para a obtenção de uma compreensão geral do texto (34\%), confirmação da compreensão do texto lido na língua estrangeira (30\%), agilidade na tradução de textos (22\%) e conseguir uma tradução rápida para editar o que for necessário (14\%).

0 Google Tradutor também apresenta outros serviços acoplados à ferramenta, como tradutor de sites e de documentos e a opção de ouvir a pronúncia das palavras. Ao serem questionados, os usuários informaram os mais utilizados, podendo apontar mais de uma ferramenta:

1. Tradutor automático de palavras ou frases (68\%)

2. Pronúncia (ouvir o que foi digitado) (62\%)

3. Tradutor de sites (51\%)

4. Utilização do microfone para entrada do termo de busca (13\%)

5. Translator Toolkit - tradutor de documentos (5\%)

O serviço de "tradução de palavras ou frases", presente em $68 \%$ das respostas, é o serviço mais conhecido e utilizado. Ele foi o primeiro a ser lançado e ainda é líder de utilização. O "tradutor de sites", também antigo, foi indicado em $51 \%$ das respostas dos alunos. A compreensão auditiva representa $62 \%$ das respostas no serviço de "ouvir o que foi digitado", demonstrando a necessidade de confirmar a pronúncia das palavras. Mesmo com constantes melhorias e implantações, nem todos os serviços são conhecidos ou utilizados. De toda a pesquisa, somente um aluno apontou conhecer ou usar todos os serviços oferecidos. 


\subsection{ANÁLISE DE TEXTOS TRADUZIDOS PELO GOOGLE TRADUTOR (GT)}

Nesta seção, serão apresentados excertos das traduções geradas pelos trechos de textos aplicados no Google Tradutor. ${ }^{6}$ As traduções aqui sugeridas são de nossa responsabilidade e outras versões são possíveis.

1) Referência indicada pelo curso de Arquitetura. Foi inserido na TA um parágrafo de um artigo de cinco páginas.

EISENMAN, P. Visions' unfolding: Architecture in the age of electronic media. Roemer Van Toorn, c2012. Disponível em: বttp:/ / www. roemervantoorn. nl/ Resources/ Peter\%20Eisenman\%20Art icle.pdf>. (05/ 08/2012).

\section{Excerto 1}

Since architecture has traditionally housed value as well as fact one would imagine that architecture would have been greatly transformed.

A arquitetura tem um valor tradicionalmente abrigado, bem como o fato se poderia imaginar que a arquitetura teria sido muito transformada.

A estrutura sintática foi alterada completamente ao não iniciar a oração com a conjunção "since" que dá a ideia de razão, motivo, traduzida como "uma vez que". O sentido ficou comprometido porque no texto original o conceito de arquitetura incorpora "valor e obra".

O verbo "house" - abrigar, acomodar, conter - aparece em sua forma de particípio passado e conectado ao substantivo "valor" tendo assim "valor abrigado".

${ }^{6}$ Traduções sugeridas pela ferramenta no dia 26/ 08/ 2012. 
COSTA, G. C.; DANIEL, F. de G. - Google Tradutor: Análise de Utilização e Desempenho da Ferramenta

A ausência de pontuação no texto original foi um elemento complicador no excerto acima. Percebe-se o uso do "one" como suj eito impessoal, em que a ferramenta corretamente sugeriu "one would imagine" como "se poderia imaginar, seria possível imaginar". Entretanto, a tradução da ferramenta perde completamente o sentido separando os substantivos "value" e "fact", que deveriam vir juntos em "a arquitetura tradicionalmente integra fato e valor", ao invés de trazer "fact" complementando o sujeito impessoal em "o fato se poderia imaginar".

Finalmente, é visível que os desvios mais sérios são os de origem morfossintática e que houve comprometimento do sentido geral do trecho.

\section{Excerto 2}

But this is not the case, for architecture seems little changed at all.

\section{Mas isto não é o caso, para a arquitectura parece pouco mudou.}

Observa-se neste excerto "architecture" como "arquitectura". O português utilizado foi o de Portugal. Ao abrir as opções de idiomas, ele não indica português do Brasil ou de Portugal, usando-o de maneira genérica, sem regionalismos.

Outro desvio foi com relação ao termo "changed". O GT não conseguiu identificá-lo como particípio do verbo, assumindo apenas como verbo no passado, mas ainda assim a compreensão da locução é possível.

O principal problema envolveu "for" que pode ser uma preposição ou conjunção. No texto original sua função específica é a de conjunção que poderia ser substituída por "because" e, no português, "uma vez que, pois". Entretanto, houve uma troca pela preposição "para", o que pode gerar má compreensão do trecho. No original, a arquitetura é o suj eito da mudança. 


\section{Excerto 3}

Metaphors such as house and home; bricks and mortar; foundations and shelter, attest to architecture's role in defining what we consider to be real.

Metáforas como casa e de casa; tijolos e argamassa, fundações e abrigo, atestam o papel da arquitetura na definição daquilo que nós consideramos ser real.

A definição de "house and home" tem um significado simbólico. "House" está se referindo a "casa" com um conceito de construção e mais concreto, sem sentimentalismos. "Home" trata não só do abrigo, mas do "lar", envolvendo sentimento em sua definição, portanto, um conceito abstrato. A ferramenta não conseguiu fazer essas diferenciações devido à pluralidade de significados. É possível que um tradutor humano faça a adequação sem maior dificuldade, mas não é tarefa fácil para a ferramenta.

\section{Excerto 4}

Clearly, a change in everyday concepts of reality should have had some effect on architecture.

Claramente, uma mudança de conceitos cotidianos da realidade deve ter tido algum efeito sobre a arquitetura.

O verbo "should" não teve sua tradução no tempo verbal correto. Ainda que, ao clicar nas traduções alternativas, ele mostre como a forma "deveria", a mesma apresenta-se somente como terceira opção. "Arquitetura" foi traduzida neste trecho para o português do Brasil, sugerindo que houve uma mudança na fonte do banco de dados. 
COSTA, G. C.; DANIEL, F. de G. - Google Tradutor: Análise de Utilização e Desempenho da Ferramenta

2) Referência indicada pelo curso de Ciências da Computação. Foi inserido na TA um parágrafo de um artigo de 21 páginas.

Greenwood, D.; Khaj eh-hosseini, A.; Smith, J. W.; Sommervillee, I. The cloud adoption toolkit: Supporting cloud adoption decisions in the enterprise. School of computer science, 2010. Disponível em: <http:// www.cs.st-

andrews. ac. uk/ -ifs/ Research/ Publications/ Papers-PDF/ 2010-

/ CloudAdoptionToolkit. pdf>. (27/ 07/ 2012).

\section{Excerto 5}

Cloud computing represents a shift away from computing as a product that is owned, to computing as a service that is delivered to consumers over the internet from large-scale data centers - or 'clouds'.

Cloud computing representa uma mudança da computação como um produto que é de propriedade, para a computação como um serviço que é entregue aos consumidores através da Internet a partir de centros de dados em grande escala - ou 'nuvens'.

O termo "cloud computing" é técnico e específico da área, mas já é aplicado em português como sendo "computação em nuvem". Se clicarmos em sugestões, o termo traduzido aparece como uma das opções. A escolha de um termo ou de outro não afeta a compreensão do texto. A compreensão geral do trecho é possível.

\section{Excerto 6}

Cloud computing is currently being exploited by technology start-ups due to its marketed properties of scalability, reliability and cost-effectiveness. 
A computação em nuvem está sendo explorada por empresas iniciantes de tecnologia devido às suas propriedades comercializadas de confiabilidade, escalabilidade e custo-efetividade.

O termo "cloud computing" aparece neste trecho traduzido. Percebe-se então que não há padrão para a manutenção do termo técnico em língua original ou sua tradução. Cabe ao usuário escolher uma das opções.

O único desvio mais notável neste trecho recai sobre "marketed properties", que pode ser traduzido como "propriedades comerciais" ou, explicando o termo no contexto, a computação em nuvem é "altamente comercializável". No geral, os sentidos foram preservados.

\section{Excerto 7}

However, at present much ambiguity and uncertainty exists regarding the actual realization of these promised benefits, as there is currently much hype, particularly around the cost savings of cloud computing which are based on simplistic assumptions.

No entanto, a ambigüidade muito presente e incerteza existe sobre a efetiva realização desses benefícios prometidos, como não é hype atualmente muito mais, particularmente em torno da redução de custos da computação em nuvem, que são baseadas em suposições simplistas.

"At present" perdeu a função de advérbio de tempo porque foi considerado pelo GT como "muito presente", intensificando o adjetivo presente, desestabilizando os sentidos dos termos seguintes "much ambiguity and uncertainty exist".

"There is" perdeu o significado de verbo conjugado na afirmativa para um na negativa, mesmo com a ausência do "not, no" no original. 
COSTA, G. C.; DANIEL, F. de G. - Google Tradutor: Análise de Utilização e Desempenho da Ferramenta

Não houve adequação quanto às mudanças ortográficas na língua portuguesa, pois há o uso do trema.

"Hype" não recebeu uma tradução e teve o termo mantido em inglês, o que impossibilitou a tradução dos próximos termos na frase. 0 termo significa propaganda agressiva e constante.

"Actual realization of these promised benefits" com a tradução do GT como "a efetiva realização desses benefícios prometidos" também perdeu seu sentido, pois teríamos "percepção real [ou efetiva] desses benefícios prometidos".

3) Referência indicada pelo curso de Engenharia Química. Foi inserido na TA um parágrafo de um artigo de seis páginas.

TREYBAL, R. E. Adiabatic gas absorption and stripping in packed towers. ACS Publications, c2012. Disponível em: বhttp:// pubs. acs. org/ doi/ abs/ 10.1021/ ie50715a009>. (05/ 08/ 2012).

\section{Excerto 8}

The general approach here is similar to that of Olander $(9,10)$, who dealt with a problem involving no mass transfer in the liquid.

A abordagem geral é semelhante ao do Olander $(9,10)$, que se tratou de um problema que não envolve nenhuma transferência de massa no líquido.

A tradução desse trecho está quase perfeita, com os sentidos sendo mantidos. Os desvios envolveram tempo verbal e uso de artigo no gênero correto. 


\section{Excerto 9}

Allowance is made for both absorption of a single solute and evaporation or condensation of solvent.

Provisão é feita tanto para a absorção de um soluto único e evaporação ou condensação do solvente.

Neste excerto, a ferramenta produz uma tradução quase perfeita, mas falha em dar o termo-chave que é "allowance". Foi sugerida a tradução "provisão", pois o termo é muito utilizado com o sentido de "subsídio, ajuda financeira, mesada, provisão". Em química refere-se à absorção ou redução na reação química.

\section{Excerto 10}

Modification of the method, if not the execution of it, is readily made for a multiplicity of solutes. Axial dispersion is not accounted for, but the indications are (3) that this effect may be minor; in any event, adequate means to estimate this at the interfacial surface is the same for heat and mass transfer, which is true if the packing is adequately irrigated.

Modificação do método, se não a execução do mesmo, é prontamente feita para uma multiplicidade de solutos. Dispersão axial não é contabilizado, mas as indicações são (3) que este efeito pode ser menor, em qualquer caso, os meios adequados para estimar esta na superfície interfacial é a mesma para a transferência de calor e de massa, o que é verdadeiro se a embalagem é adequadamente irrigada.

O GT, ao fazer a tradução do inglês para o português, não aplica os artigos "a, o", o que não impede na compreensão das frases. Percebe-se 
COSTA, G. C.; DANIEL, F. de G. - Google Tradutor: Análise de Utilização e Desempenho da Ferramenta

neste trecho a expressão "account for" que pode realmente ser "contabilizado", mas no texto a melhor tradução seria "considerada".

Finalmente, é possível notar que a conjugação verbal do verbo "to be" "é" foi trazida em sua forma de presente do indicativo. Em caso de uso do "if", indicativo de condicional e, portanto, subjuntivo, a forma correta seria "for" (para futuro) ou "caso a embalagem seja [presente] adequadamente irrigada". 0 trecho, porém, é bem compreendido na língua-alvo devido a suas características técnicas.

De maneira geral, alguns desvios foram mais comuns nas traduções da ferramenta. Houve mudanças na estrutura do trecho traduzido em relação ao original que comprometeram o sentido do texto para o usuário. Também houve dificuldades morfossintáticas causadas pelo fato de a ferramenta ter confundido classes gramaticais e tempos verbais. Em casos em que há pluralidade de sentidos, a primeira tradução apresentada pelo GT nem sempre correspondeu ao sentido mais adequado do termo dentro da oração. Notou-se que a ferramenta usa o português de Portugal e do Brasil sem diferenciação, além de não seguir uma tradução padronizada de termos.

Finalmente, nota-se que a qualidade da tradução está também ligada ao tipo de texto que é aplicado, evidenciando que, se o mesmo for técnicocientífico, pela baixa recorrência de pluralidade de sentidos, a tradução permite que o usuário tenha uma compreensão geral do texto. Para aqueles que têm proficiência razoável no idioma, é possível identificar os erros para confirmar sua compreensão do texto.

Logo, percebe-se pela afirmação dos usuários que a ferramenta atinge suas expectativas, conforme gráfico que se segue: 


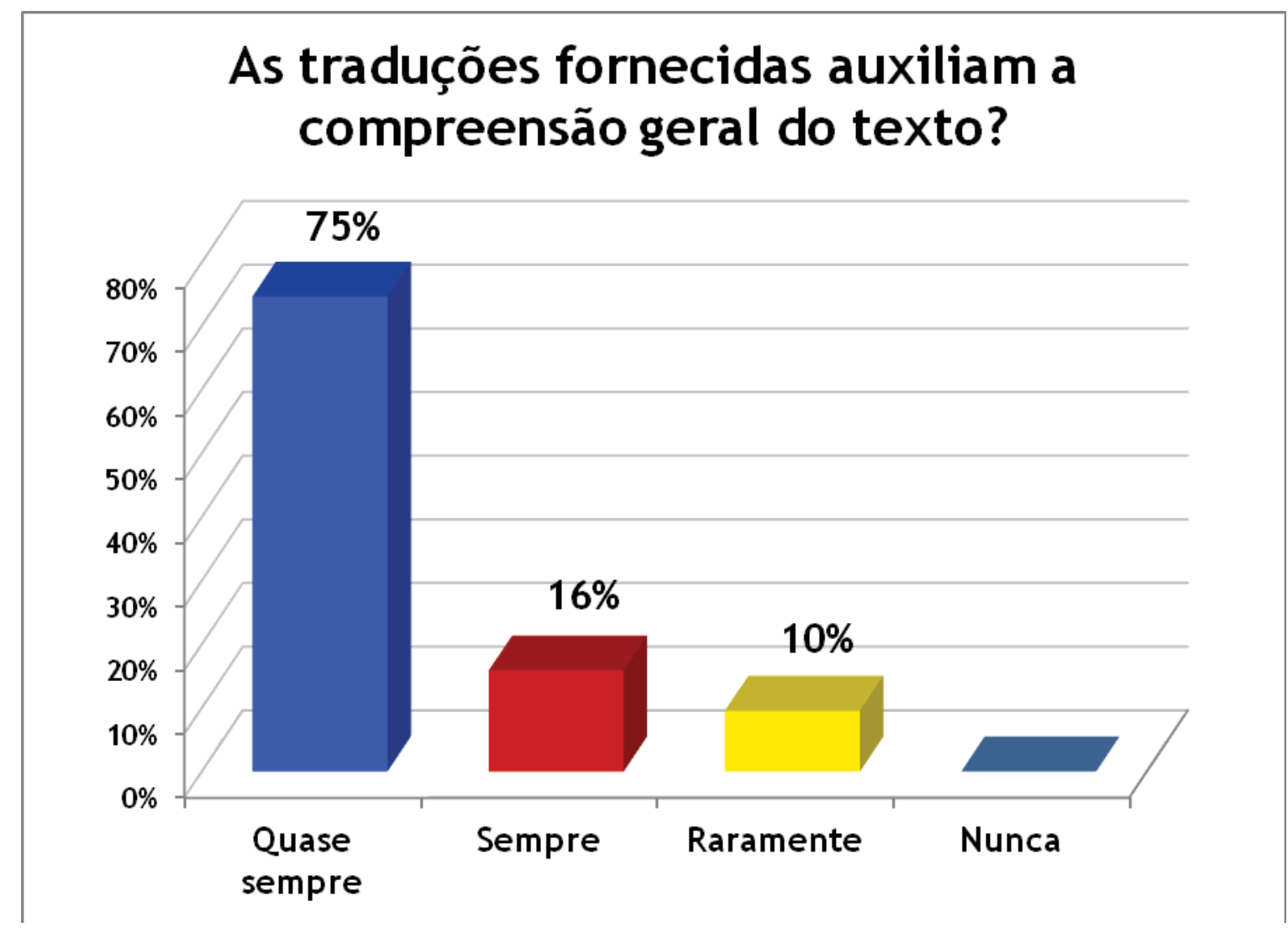

Gráfico 9 - Nível de compreensão GT

Conclui-se, portanto, após a discussão dos dados desta investigação, que os participantes em sua maioria são usuários da ferramenta, possuem alto grau de confiabilidade em sua eficácia e a mesma atende parcialmente suas expectativas, isto é, uma tradução que permita uma compreensão textual mínima.

\section{Considerações Finais}

Após o curso desta pesquisa, foi possível observar que os estudos a respeito da ferramenta são ainda escassos, mesmo após alguns anos de sua criação. A falta de conteúdo bibliográfico específico pode levar ao desconhecimento de suas funcionalidades, o que pode ser refletido em 
COSTA, G. C.; DANIEL, F. de G. - Google Tradutor: Análise de Utilização e Desempenho da Ferramenta

preconceito quanto a seu uso ou em opinião errônea quanto à qualidade das traduções apresentadas.

Ao conhecer mais profundamente a ferramenta, há a possibilidade de se tornar um usuário mais crítico e aproveitar melhor a evolução tecnológica e a praticidade que ela oferece. Tratando-se de tecnologia, as evoluções ocorrem rapidamente. No início do projeto, eram 57 línguas que o Google Tradutor tinha cadastradas em seu banco de dados e o número aumentou para 71. Assim como o aumento dos idiomas no banco de dados, houve inserção e atualização de serviços, auxiliando em seu desempenho para traçar características cruciais quanto ao seu uso e capacidade de auxílio à atividade de tradução, a qual é tão complexa diante de nossas línguas dinâmicas.

Retomando as perguntas que nortearam o estudo, é correto afirmar que, no contexto desta investigação, a ferramenta é muito utilizada, principalmente por universitários de menor faixa etária. São usuários que se declaram tendo nível de proficiência linguística entre iniciante (básico) e intermediário, com maioria na utilização para textos em língua inglesa, o que reforça a importância do aprendizado deste idioma no mundo atual. Apesar de os resultados apontarem para uma confiabilidade parcial na tradução produzida, não foi possível perceber preconceitos que impeçam o uso da ferramenta.

O estudo demonstra que os usuários, independentemente do nível declarado de proficiência, sentem-se seguros em decidir optar por uma ferramenta de auxílio ou não. A maioria que participou da pesquisa utiliza o Google Tradutor e confia em sua capacidade de auxiliar na compreensão geral dos textos em língua inglesa. Por essa razão, os motivos mais frequentes nas respostas a respeito da procura pelas traduções fornecidas pela ferramenta são para obter essa compreensão geral e confirmar a compreensão que tiveram do texto.

Quanto à eficácia da ferramenta, conclui-se que ela pode auxiliar os usuários em textos técnicos de língua inglesa, pois estes possuem principalmente características monossêmicas. 
Os desvios apresentados pela ferramenta envolveram escol has lexicais e, como a ferramenta utiliza dados estatísticos, as traduções mais recorrentes são as mais sugeridas. Nota-se também que os desvios mais significativos envolveram as modificações que a ferramenta fez da estrutura do original, trocas de classes gramaticais e tempos verbais, a não padronização de termos e a dificuldade em adequar um termo quando há pluralidade de sentidos, dificultando a compreensão completa da oração. Embora tenham ocorrido esses desvios, a compreensão geral dos parágrafos foi possível.

Para pesquisas posteriores, seria interessante fornecer ao entrevistado uma classificação de níveis de proficiência para que a escolha do nível seja feita embasada em conteúdo pré-determinado, não apenas na perspectiva pessoal.

Como afirmado por SANTOS (2006), a tradução constrói, é processo e resultado, estabelecendo uma relação bidirecional entre dois lados comunicativos. Com a evolução tecnológica e a globalização, a necessidade de se comunicar está ainda mais presente. Da mesma maneira que nossas línguas são dinâmicas, a tecnologia também vem se renovando a cada dia para diminuir ou derrubar as barreiras culturais, fazendo com que consigamos nos comunicar, ou ao menos tentar, em qualquer idioma.

\section{Referências bibliográficas}

ACTFL PROFICIENCY GUIDELINES 2012. American council on the teaching of foreign languages, 2012. Disponível em: বhttp:// www. actfl.org/ files/ public/ ACTFLProficiencyGuidelines2012_ FINAL. pdf >. (25/08/2012).

ALFARO, C. Descobrindo, compreendendo e analisando a tradução automática. Rio de Janeiro: PUC-Rio, 1998. Disponível em: বttp:// www. tecgraf. pucrio. br/ carolina/ monografia/ apresentacao. html>. (08/01/2011).

Alfaro, C.; Dias, M. C. P. Tradução automática: Uma ferramenta de auxílio ao tradutor. Cadernos de tradução, Florianópolis, v. 1, n. 3, 1998, pp. 369-390. 
COSTA, G. C.; DANIEL, F. de G. - Google Tradutor: Análise de Utilização e Desempenho da Ferramenta

em: বhttp:// www. periodicos. ufsc. br/ index. php/ traducao/ article/ view / 5392/ 4936>. (08/01/2011).

ARAújo, J. P. DE. Tradução automática de abstracts: Avaliação do potencial e das limitações de três ferramentas da Web. Linguagem em (dis)curso, Tubarão, v. 3, n. 1, jul./dez. 2002, pp. 69-107. Disponível em: «ttp:// www3. unisul. br/ paginas/ ensino/ pos/linguagem/ 0301/ 5\%20ar t\%203\%20P. pdf >. (26/03/2011).

ARAÚj O, J. P. DE. Tradutores experientes falam sobre a tradução automática. Tudo 2.0, c2010. Disponível em: বhttp:// www.comunicar. pro.br/artigos/ tradut_exp. pdf>. (26/03/2011).

Benedetti, I. C; Sobral, S. (Org). Conversas com tradutores: Balanços e perspectivas da tradução. 2 ed. São Paulo: Parabóla Editorial, 2003. $213 p$.

BeRnABIO, G. B. A Tradução automática: 0 desempenho dos sistemas Google Translate e Babelfish. Bauru: USC, 2010. Disponível em: বhttp: / / lucivillelatranslation. files. wordpress. com/ 2011/ 01/ gil bertomonografial. pdf>. (26/03/2011).

BRUM, F. Os sistemas de tradução automática. In: As novas tecnologias e o trabalho do tradutor: Guia prático. Üniversidade Aberta, 2008. Disponível em: বhttp:// repositorioaberto. univab. pt/ bitstream/ 10400. 2/ 1224/ 1/ Fernando\%20Brum\%2020Mestrado\%20em\%20Estudos\%20de\%20Tradu\%C3\%A7\%C3\%A30. pdf > . (10/04/2011).

Coelho, H. S. H. É possível aprender inglês na escola? Crenças de professores e alunos sobre 0 ensino de inglês em escolas públicas. In: Crença de professores em pré-serviço. Belo Horizonte: Faculdade de Letras UFMG, 2005. Disponível em: বhttp:// www. bibliotecadigital. ufmg. br/ dspace/ bitstream/ 1843/ ALDR -6ACG69/1/ disserta__o_pdf_hilda_coelho. pdf >. (26/08/2012).

EISENMAN, P. Visions' unfolding: Architecture in the age of electronic media. Roemer Van Toorn, c2012. Disponível em: বhttp:// www. roemervantoorn. nl/ Resources/ Peter\%20Eisenman\%20Art icle. pdf >. (05/ 08/2012).

Franz J OSEF OCH. Research at Google, c2012. Disponível em: «ttp:// research. google.com/ pubs/ och. html>. (27/ 05/ 2012).

GOMES, L. Computers: Will they ever learn? Forbes Asia Magazine, ago. 2010. Seção: Digital Tools. Disponível em: 
বhttp:/ / www. forbes. com/ global/ 2010/ 0809/ columnists-lee-gomesdigital-tools-computers-will-they-learn. html>. (17/ 04/ 2011).

Google History. Google, c2012. Disponível em: বhttp:// www. google.com/ corporate/ history. html>. (27/ 05/ 2012).

Greenwood, D.; Khaj eh-hosseinI, A.; Smith, J. W.; Sommerville, I. The cloud adoption toolkit: Supporting cloud adoption decisions in the enterprise. School of computer science, 2010. Disponível em: <http:// www.cs.standrews. ac. uk/ ifs/ Research/ Publications/ Papers-PDF/ 2010/ CloudAdoptionToolkit. pdf>. (27/ 07/ 2012).

Inside Google Translate: Find out how our translations are created. Google, c2013. Disponível em: «ttp:// translate. google.com/about/ >. (19/ 10/ 2013).

J anUlevičliené V.; Kavaliauskiené K. Promoting the fifth skill in teaching ESP. English for specific purposes world, 2002. Disponível em: <http:// www. espworld.info/ Articles_2/ Promoting\%20the\%20Fifth\%20Skill\%20in\%20T eaching\%20ESP. html>. (25/08/2012).LEAL, L. Programas de computador farão o trabalho braçal do tradutor. Revista Época, São Paulo, maio 2009. Seção: Ciência e Tecnologia. Disponível em: বttp:// revistaepoca. globo. com/ Revista/ Epoca/ 0, EMI7121215224,00. html >. (17/ 04/ 2011).

LIMA, L. R. Tradução eletrônica: Do riso irônico ao interesse científico. Fólio Revista de Letras, Vitória da Conquista, v. 3, n. 1, jan/jun. 2011. Disponível em: বhttp:// periodicos. uesb. br/ index. php/ folio/ article/ viewFile/ 558/ $626>$. (29/01/2012).

MARTINS, T. H. B. Reflexões sobre a formação de professores de inglês como língua estrangeira. Revista de Educação, Valinhos, v. 10, n. 10, 2007. Disponível em: «ttp:// sare. unianhanguera. edu. br/ index. php/ reduc/ article/ view/ 22 $8 / 226>$. (26/08/2012).

Murano, E. Tradução com toque humano. Revista Língua Portuguesa, São Paulo, ed. 56, jun. 2010. Seção: Internet. Disponível em: 〈tttp:/ / revistalingua. uol.com. br/ textos. asp?codigo $=12047$ >. (17/ 04/ 2011).

MURPHY, S. Google Translate draws 200 million users each month. Mashable, Nova lorque, 26 abr. 2012. Seção: Tech. Disponível em: বttp:/ / mashable.com/ 2012/ 04/ 26/ google-translate-users/ >. (26/08/2012). 
PAVÃo J ÚNIOR, J. A língua do Google. Revista Veja, vol. 43, n. 18, São Paulo: maio 2010, pp. 122-131.

Resende, N. R.; SouzA, A. C. A atividade tradutória e a relevância da leitura: Legibilidade e leiturabilidade de textos humorísticos traduzidos. Revista Gatilho, J uiz de Fora, ano VII, n. 13, set. 2011. Disponível em: বhttp:/ / www. ufjf. br/ revistagatilho/ files/ 2011/ 10/ resende. pdf>. (12/ 02/ 2012).

RINO, L. H. M; SPECIA, L. Introdução aos métodos e paradigmas de tradução automática. São Carlos: NILC-ICMC-USP, 2002. Disponível em: বttp:/ / www2. dc. ufscar. br/ -ucia/ TechRep/ NILCTR0204SpeciaRino. pdf>. (26/03/2011).

SANTOS, D. A Tradução na sociedade do conhecimento ou tradução: Uma tecnologia de ponta ou ciência e tradução. Linguateca, 2006. Disponível em: ঝttp:/ / www.linguateca.pt/ Diana/ download/ SantosSeminTradCiencia 2006actas. pdf>. (17/ 04/2011).

SÃo Paulo em Foco - Gerações X, Y e Z. Quest: Inteligência de mercado, 2011. Disponível em: 〈http:// www.questmkt. com.br/ questblog/ ?p=172>. (20/08/ 2012).

SMAAL, B. Qual a ferramenta online mais confiável para se traduzir textos? Tecmundo, 2010. Disponível em: ঝttp:/ / www.tecmundo.com. br/ 4022-qual-a-ferramenta-online-maisconfiavel-para-se-traduzir-textos-. htm>. (29/01/2012).

TREybal, R. E. Adiabatic gas absorption and stripping in packed towers. ACS Publications, c2012. Disponível em: বhttp:/ / pubs. acs. org/ doi/ abs/ 10.1021/ ie50715a009>. (05/ 08/ 2012). 